\title{
A comprehensive assessment using COPD assessment test scoring and modified Medical Research Council dyspnea scoring is necessary for personalized therapy for COPD patients
}

\author{
This article was published in the following Dove Press journal: \\ International Journal of COPD \\ 15 October 2015 \\ Number of times this article has been viewed
}

\section{Shinji Teramoto' \\ Toshihide Inui ${ }^{2}$ \\ Nobuyuki Hizawa ${ }^{3}$ \\ 'Department of Pulmonary Medicine, Hitachinaka Medical Education and Research Center, University of Tsukuba, Ibaraki, Japan; ${ }^{2}$ Department of Pulmonary Medicine, Hitachinaka General Hospital, Hitachi Ltd, Ibaraki, Japan; ${ }^{3}$ Department of Pulmonary Medicine, Graduate School of Comprehensive Human Science, University of Tsukuba, Ibaraki, Japan}

Correspondence: Shinji Teramoto Hitachinaka Medical Education and Research Center, University of Tsukuba, 20-I Hitachinaka-shi, Ishikawa-cho, Ibaraki, 3|2-0057, Japan

Tel +8 I 293545 I I I

Fax +81293545926

Email shinjit-tky@umin.ac.jp

\section{Dear editor}

In a recent issue of the International Journal of COPD, Rhee et al ${ }^{1}$ have demonstrated considerable discrepancies between modified Medical Research Council (mMRC) dyspnea scoring and COPD assessment test (CAT) scoring in patients with COPD. The current data are also supported by the findings described in another article, which indicates that more than $50 \%$ of COPD patients show discrepancies between the severity of CAT scores and that of mMRC scores in the real world. ${ }^{2}$

In principle, CAT and mMRC scores are not correlated. The CAT scoring is for continuous variables, while mMRC scoring is for categorical variables. Furthermore, the severity of CAT scores is not correlated with that of the Global Initiative for Chronic Obstructive Lung Disease (GOLD) staging. Because CAT scoring is based on eight different items, the sleep disturbance score 5 is not correlated with the cough/sputum symptom score 5 or with the exertional dyspnea score 5 . This justifies the discrepancy found between the scores in the two scoring systems.

The study by Rhee et al ${ }^{1}$ strongly indicates that comprehensive assessment using both the CAT and the mMRC dyspnea scoring systems is necessary for personalized therapy for COPD patients. The evaluation of health status and the assessment of dyspnea severity suggest the different aspects of pathophysiology of COPD patients. However, there is a problem in COPD practice and research at the current juncture. By searching PubMed literature of the past 5 years using keywords "CAT" and "COPD", 280 papers were extracted. However, a search using the keywords "mMRC" and "COPD" extracted less than half this number (135 papers). Unfortunately, a search using all keywords "CAT", "mMRC", and "COPD" extracted very few papers (46 papers, 16.4\% of the number of papers extracted using the search terms "CAT" and "COPD"). Therefore, it is reasonable to speculate that mMRC and CAT assessment may not be performed simultaneously for the assessment of COPD patients in clinical practice.

The CAT and mMRC scores are affected differently by bronchodilator therapy in COPD patients. ${ }^{3}$ Ohno et al $^{3}$ demonstrated that a novel, once-daily inhaled longacting beta 2-agonist, indacaterol, improved pulmonary function variables, mMRC dyspnea scale score, and CAT scores. However, a switch in replacement therapy from salmeterol to indacaterol significantly improved the mMRC and forced vital capacity 
values, but did not significantly improve the CAT scores or other pulmonary function variables. ${ }^{3}$

Importantly, mMRC and CAT assessments can be used to predict the prognosis of COPD patients. The COPD History Assessment in Spain (CHAIN) study revealed that the CAT could be used for predicting all-cause mortality in patients with COPD, but was inferior to mMRC dyspnea scores in this respect. ${ }^{4}$ COPD patients who died had higher CAT and MRC dyspnea scores than survivors. Unfortunately, the CHAIN study used original MRC scores instead of mMRC scores.

When personalized therapy for different phenotypes of COPD is implemented, bidirectional assessment using CAT and mMRC scoring will be necessary in clinical settings, in addition to assessment of pulmonary function and presence of inflammatory indicators in exhaled breath, sputum, and blood.

\section{Disclosure}

The authors report no conflicts of interest in this communication.

\section{References}

1. Rhee CK, Kim JW, Hwang YI, et al. Discrepancies between modified Medical Research Council dyspnea score and COPD assessment test score in patients with COPD. Int J Chron Obstruct Pulmon Dis. 2015;10:1623-1631.

2. Price DB, Baker CL, Zou KH, Higgins VS, Bailey JT, Pike JS. Real-world characterization and differentiation of the Global Initiative for Chronic Obstructive Lung Disease strategy classification. Int J Chron Obstruct Pulmon Dis. 2014;9:551-561.

3. Ohno T, Wada S, Hanada S, Sawaguchi H, Muraki M, Tohda Y. Efficacy of indacaterol on quality of life and pulmonary function in patients with COPD and inhaler device preferences. Int J Chron Obstruct Pulmon Dis. 2014;9:107-114.

4. Casanova C, Marin JM, Martinez-Gonzalez C, et al; COPD History Assessment in Spain (CHAIN) Cohort. Differential effect of modified Medical Research Council dyspnea, COPD Assessment Test, and clinical COPD questionnaire for symptoms evaluation within the new GOLD staging and mortality in COPD. Chest. 2015;148:159-168. 


\section{Authors' reply}

\section{Chin Kook Rhee}

Division of Pulmonary, Allergy and Critical Care Medicine, Department of Internal Medicine, Seoul St Mary's Hospital, College of Medicine, The Catholic University of Korea, Seoul, Republic of Korea

Correspondence: Chin Kook Rhee

Division of Pulmonary, Allergy and Critical Care Medicine, Department of Internal Medicine, Seoul St Mary's Hospital, College of Medicine, The Catholic University of Korea, 222 Banpodaero, Seochogu, Seoul, 0659I, Republic of Korea

Tel +82 222586067

Fax +82 25993589

Email chinkook@catholic.ac.kr

\section{Dear editor}

In a recent letter to the Editor of the International Journal of $C O P D$, Teramoto et al suggested bidirectional assessment using the COPD assessment test (CAT) and the modified Medical Research Council (mMRC) dyspnea score in COPD patients. However, there may be two questions regarding this suggestion. Do clinicians measure two different scores for all COPD patients? Can one score replace the other score? To help answer these questions, we have further analyzed our cohort data of previous publication (Korean COPD Subtype Study [KOCOSS] cohort, $\mathrm{n}=790){ }^{1}$
In our previous study, ${ }^{1}$ we showed that there was discrepancy between the CAT and mMRC scoring systems. We have further analyzed if there was still discrepancy between CAT score for breathlessness and mMRC dyspnea score. The fourth question in the CAT is a score for breathlessness when the patient walks up a hill or one flight of stairs. Since both the $\mathrm{mMRC}$ and the fourth CAT score are questions regarding dyspnea, it is expected that there may be close correlation between these two scores. If this is the case, the mMRC score may be replaced by the fourth CAT score.

However, there was still discrepancy between the CAT score for breathlessness and the mMRC dyspnea score. Interestingly, a histogram of the fourth CAT score according to the mMRC showed wide variation in the CAT score for breathlessness in each mMRC group (Figure 1). Moreover, the percentage of CAT score for breathlessness in each mMRC group was also variable (Figure 2). For example, among patients with mMRC score of $0(n=69), 14.5 \%$ of patients $(n=10)$ scored (marked) 3 point in fourth CAT question.

Despite the discrepancies, the fourth CAT score and mMRC score are similar questions regarding dyspnea; however, the answers for these two questions were different. This is a rather surprising result, because mMRC is an indicator of breathlessness. Also, this result could suggest
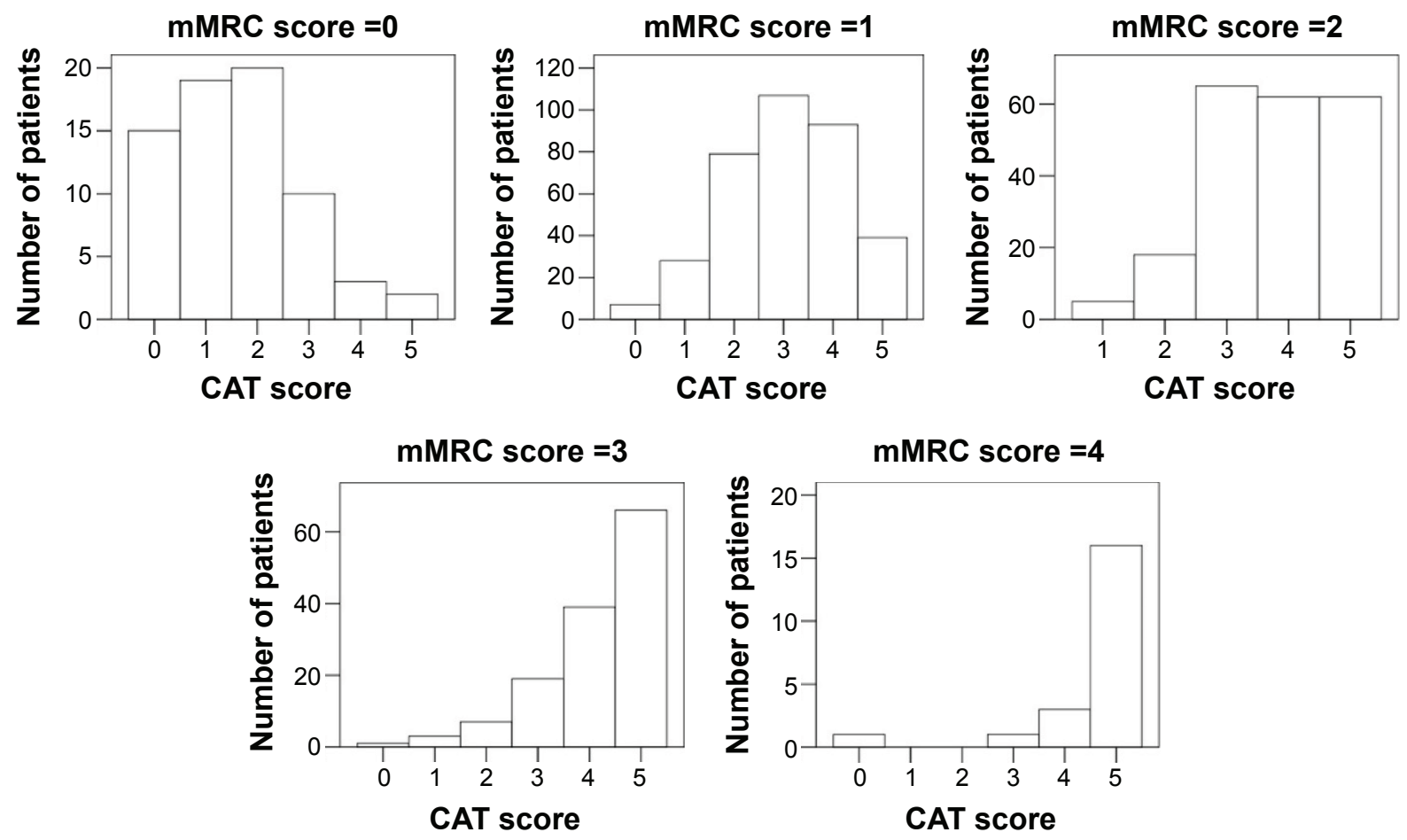

Figure I Histogram of CAT scores for breathlessness according to mMRC score.

Abbreviations: CAT, COPD assessment test; mMRC, modified Medical Research Council. 


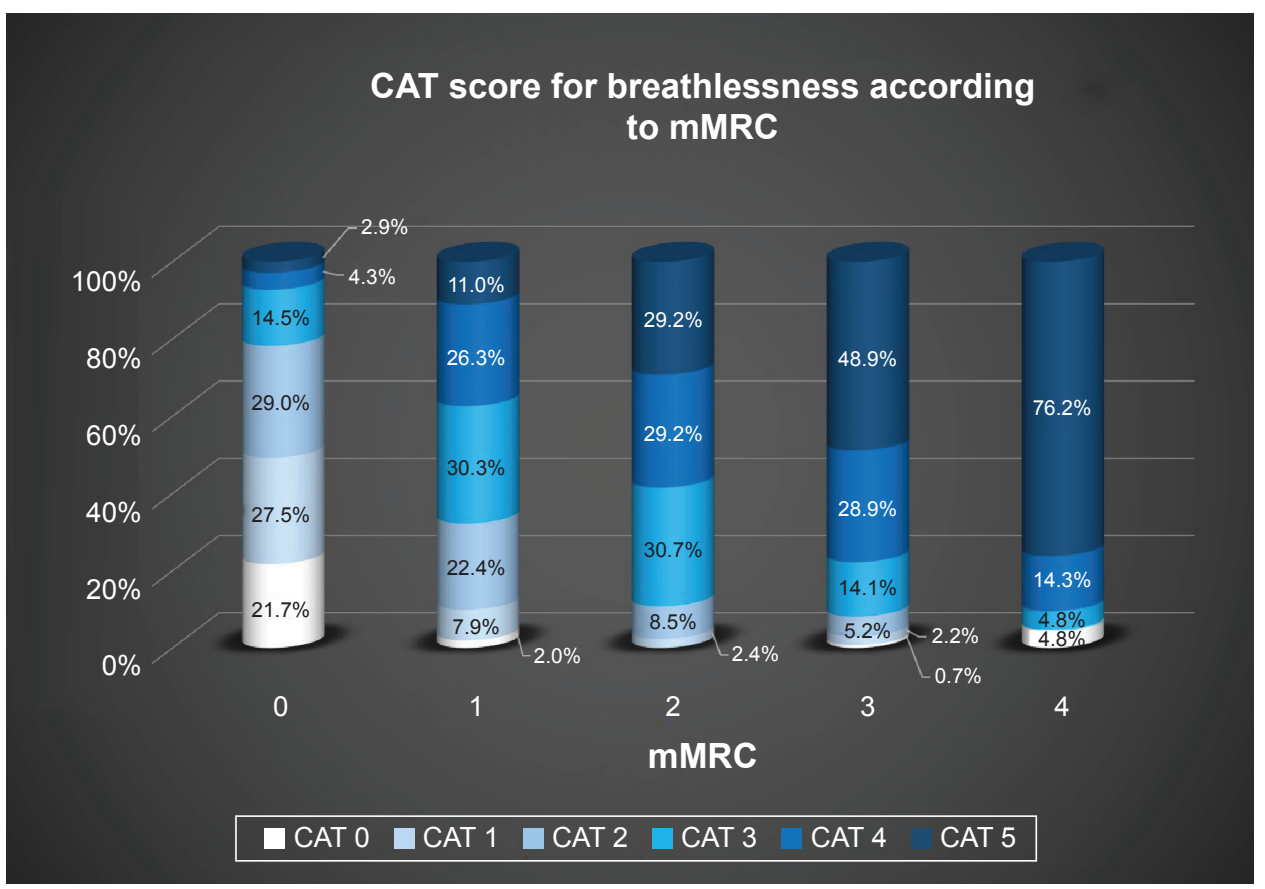

Figure 2 Distribution of CAT scores for breathlessness according to mMRC dyspnea score. Abbreviations: CAT, COPD assessment test; mMRC, modified Medical Research Council.

that CAT score for breathlessness cannot be identical with mMRC score and that it cannot be used as a surrogate for the mMRC score.

In conclusion, there was still discrepancy evident, even between the fourth CAT score and the mMRC score. Therefore, CAT score for breathlessness cannot replace mMRC score.

\section{Disclosure}

The author reports no conflicts of interest in this communication.

\section{Reference}

1. Rhee CK, Kim JW, Hwang YI, et al. Discrepancies between modified Medical Research Council dyspnea score and COPD assessment test score in patients with COPD. Int J Chron Obstruct Pulmon Dis. 2015;10: $1623-1631$.

Dove Medical Press encourages responsible, free and frank academic debate. The content of the International Journal of Chronic Obstructive Pulmonary Disease 'letters to the editor' section does not necessarily represent the views of Dove Medical Press, its officers, agents, employees, related entities or the International Journal of Chronic Obstructive Pulmonary Disease editors. While all reasonable steps have been taken to confirm the content of each letter, Dove Medical Press accepts no liability in respect of the content of any letter, nor is it responsible for the content and accuracy of any letter to the editor.

\section{Publish your work in this journal}

The International Journal of COPD is an international, peer-reviewed journal of therapeutics and pharmacology focusing on concise rapid reporting of clinical studies and reviews in COPD. Special focus is given to the pathophysiological processes underlying the disease, intervention programs, patient focused education, and self management protocols.

\section{Dovepress}

This journal is indexed on PubMed Central, MedLine and CAS. The manuscript management system is completely online and includes a very quick and fair peer-review system, which is all easy to use. Visit http://www.dovepress.com/testimonials.php to read real quotes from published authors. 